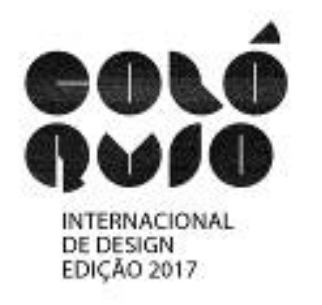

\title{
Design com minimalismo para slow fashion
}

\author{
Flávia Pereira Conti; \\ Eliete Auxiliadora Assunção Ourives; \\ Luiz Fernando Gonçalves de Figueiredo
}

resumo:

O artigo tem como objetivo a análise dos fatores positivos e negativos da aplicação de um design minimalista com enfoque no sistema slow fashion em empresas de moda, e também a exposição de empresas brasileiras que já o fazem em seu ambiente de trabalho. Para tanto, utilizou-se da ferramenta desenvolvida por Bruno-Faria e Alencar (1997), denominada "Indicadores de Clima de Criatividade" (ICC), que, por meio da análise de um ambiente criativo, busca avaliar os fatores que influenciam na expressão do potencial criador, tanto com os empregados individualmente quanto em nível organizacional. Para poder fazer tal investigação, fez-se um levantamento individual sobre design minimalista e slow fashion, analisando suas semelhanças e aplicações na história do design de moda para, à partir deste levantamento, poder fazer a aplicação das informações na ferramenta ICC.

Como resultado, obteve-se uma análise positiva do ambiente de trabalho com aplicação do design minimalista para slow fashion, observando-se uma maior liberdade de ação, incentivo à novas ideias, disponibilidade de recursos materiais, autonomia do calendário de produção e a oportunidade de repensar o sistema de Moda, abrindo novas possibilidades de criação e de produção. Como único fator ambíguo, tem-se a probabilidade de haver bloqueio de ideiais por meio de superiores, podendo este ser positivo ou não.

Como conclusão, percebe-se que a prática de um design minimalista para um sistema slow fashion é eficiente e uma oportunidade, além de criar um elo emocional com o consumidor por meio de seus artefatos, também possibilitando que a sociedade repense seu modo de consumo, observando-se a retomada de um pensamento mais crítico em cada ação, buscando uma maior conscientização, dada esta por meio de uma leitura do pensamento contemporâneo.

\section{palavras-chave:}

Minimalismo; slow fashion; design. 


\section{Introdução}

Na década de 50 surge o estilo artístico Minimal Art, que direciona sua pesquisa para uma análise fenomenológica da interação entre espaço, material, luz e observador, buscando, por meio de uma gestalt muito forte, universalizar a arte, utilizando formas geométricas e materiais industriais de forma serializada, afastando qualquer sinal de expressividade do artista e facilitando a interpretação por parte de qualquer indivíduo (FERREIRA, 2008).

Por utilizar a serialização, a arte se aproxima do design, questionando-se o papel do artista e do designer na criação do produto final. Ao fazer esta aproximação entre os dois âmbitos, cria-se um novo universo para ambos, principalmente para o design, que absorve do movimento a preocução com uma estética pura e a abstração como forma de comunicar.

Tanto no design quanto em outros âmbitos da vida, o minimalismo tem sido sinônimo de uma ferramenta que auxilia a livrar-se de excessos em prol da concentração no que é de real importância e no momento presente (NEUTE, 2013). Nota-se, então, o surgimento do movimento slow life, que implica na desaceleração da vida cotidiana e no aproveitamento do hoje (BUENO, 2016). Como vertente, tem-se o slow fashion, que muito tem se divulgado, buscando a democratização do processo de criação de forma mais lenta, com maior preocupação no desenvolvimento de processos (SARATE, 2009).

Unindo-se, então, slow fashion e minimalismo tem-se uma fusão que trabalha para um futuro responsável e sustentável, agindo localmente, porém ampliando sua ação para âmbito global, visando o bem estar dos recursos naturais e da população, com produtos que são carregados de significância, buscando-se um design refinado, materiais de qualidade e sustentáveis e uma mudança em todo o sistema de produção, criando-se uma mudança na maneira em que fabricamos, consumimos e em como vivemos (VEZZOLI, 2010).

Assim, este trabalho tem como objetivo exibir os fatores favoráveis e desfavoráveis de se aplicar o minimalismo para slow fashion em um empreendimento por meio da análise de sua teoria e contexto histórico, reafirmando-os por meio de exemplos de empresas que já vem utilizando tal combinação na criação de seus produtos e obtido resultados positivos.

\section{Procedimentos Metodológicos}

De acordo com Refosco et al. (2011) o mundo da moda contemporâneo baseado no sistema fast fashion apresenta uma série de falhas, sendo a principal dela a objetivação de números em relação a qualidade do produto e seu ciclho de vida, fazendo-se necessário a desaceleração de quase todas as formas de consumo e a priorização da criação de produtos duráveis e ecologicamente corretos.

Este estudo pode ser classificado como de natureza inferencial, abordagem qualitativa (contém análise não generalizáveis pela estatística), e com objetivos descritivo e explicativo, buscando uma nova visão sobre a realidade do minimalismo e slow fashion na Moda e explanar os motivos que se torna viável e mais positivo a aplicação de tal associação no mundo empresarial. Para tanto, utilizou-se de uma pesquisa bibliográfica e estudo analítico (Lakatos \& Marconi, 2003), atentando-se a problemática do sistema de produção de moda atual e como o minimalismo voltado para o slow fashion pode contribuir de modo positivo para o meio socio-ambiental, trabalhando a problemática de quais os fatores positivos e negativos e como pode-se empregá-lo no meio empresarial de modo que gere lucros?

Baseando-se nos estudos de Bruno-Faria e Alencar (1997), e considerando os fatores com mais correlação ao assunto em pauta, tem-se abaixo, com a imagem 1, a apresentação dos procedimentos para a análise do minimalismo para slow fashion em uma empresa. 


\section{AVALIAÇĀO DE UM AMBIENTE DE TRABALHO CRIATIVO}

\section{FATORES FAVORÁVEIS}

\section{LIBERDADE DE AÇĀO}

"Sinto-me à vontade para agir de forma diferente"

\section{INCENTIVO À NOVAS IDEIAS}

"Há incentivo para a produção de novas ideias"

\section{DISPONIBILIDADE DE RECURSOS MATERIAIS}

"Tenho os recursos necessários para a realização do meu trabalho"

\section{FATORES DESFAVORÁVEIS}

\section{EXCESSO DE SERVIÇOS E ESCASSEZ DE TEMPO}

"O excesso de serviços impede que eu tenha tempo para refletir sobre o melhor modo de realizá-los"

\section{BLOQUEIO DE NOVAS IDEIAS}

"Meu chefe imediato bloqueia minhas iniciativas no trabalho"

\section{RESISTÊNCIA À NOVAS IDEIAS}

"Nẫo aventura-se em tentar novas alternativas de trabalho"

Fonte: Os Autores (2017), adaptado de Bruno-Faria e Alencar (1997)

\section{Design minimalista}

Oriundo da revolução industrial no século XIX (DENIS, 1999), o design é "uma atividade de projeto responsável pelo planejamento, criação e desenvolvimento de produtos e serviços" (Sebrae, sem ano), podendo-se destacar a importância de tal profissão em relação aos impactos socio-ambientais, pensados durante todo o processo de produção de um produto. O design busca inovação, identidade, comunicação e qualidade, atuando em diversos níveis do setor industrial, visando atender as necessidades do usuário final. Por meio de seus aspectos funcionais, ergonômicos e visuais, o produto é desenvolvido, atualmente, de modo que adapte-se globalmente, manifestando-se por meio da qualidade e estilo (Market Design, sem ano).

O design contemporâneo tem como desafio o "desenvolvimento de soluções para questões complexas, que exigem uma visão ampliada do projeto, envolvendo produtos, serviços e comunicação, de forma conjunta e sustentável" (KRUCKEN apud. NICOLAU, 2013). Evidenciase aqui a importância que o designer carrega neste contexto, devendo buscar uma visão abrangente, desenvolver ações que proporcionem as mais diversas alternativas e uma riqueza de interpretação, por meio da interdisciplinariedade e a contínua busca por conhecimento (KRUCKEN apud. NICOLAU, 2013).

O minimalismo começou timidamente no século 19 e gradualmente foi conquistando seu espaço, tendo seu ápice nos anos 80 por meio da arquitetura. Como influência, tem-se o movimento Zen da cultura japonesa, que "transmite a ideia de liberdade e essência da vida, revelando a qualidade inerente do materiais e objetos utilizados" (COFFANI, 2015) e o design high tech, em especial quando 
se trata da escolha de materiais (FERREIRA, 2008). Sua principal característica é o bordão "menos é mais", tratando-se aqui de menos informação, tornando o produto mais interessante (MIGUEL, 2014), porém, a solução é simplista formalmente, mas "nem sempre uma simplicidade cognitiva, para facilitar o uso do objeto" (FERREIRA, 2008, p. 5).

O movimento deu-se como contraste aos exageros da década de 80, com a popular pop art, fazendo uso de cores neon, formas geométricas e cenas improváveis (ZYSKO, 2012) e movimentos pós-modernos, como o funcionalismo, movimento predominante até então na indústria, proveniente das escolas alemãs e do capitalismo americano, e o pós modernismo italiano, focando-se em uma expressividade e exagero formal como contraposição ao funcionalismo (FERREIRA, 2008). O minimalismo então apresenta produtos com inspiração mais intelectual que outros criadores que fizeram uso apenas por meio de uma linha mais clássica (MIGUEL, 2014), transmitindo-se modernidade, pureza, simplicidade, requinte e usabilidade (TORRES, 2016).

No design, apresenta grande uso em interfaces, como exteriorizado por toda a plataforma do Google e com a implementação do Windows 8, utilizando-se o conceito de flat design, traduzindo-se literalmente para "design plano", onde aplica-se uma estética mais simplificada e clássica (PRINTI, 2013). No produto, pode-se dizer que a escola Bauhaus foi pioneira, com nomes como Van Der Rohe, Walter Gropius e Marcel Breuer, mas não em sua essência, uma vez que a Bauhaus é conhecida pelo lema "a forma segue a função", e o minimalismo é postulado que "a função segue a forma". Os computadores e smartphones da empresa america Apple são outros exemplos da busca de um design minimalista em produtos, também podendo-se citar a IKEA com produtos universais e simplistas.

Na moda, teve-se início em Paris, com os japoneses, que levaram a alfaiataria masculina para o guarda-roupa feminino, de maneira suave e neutra, principalmente quando Kenzo, um dos mais influentes do movimento na moda, incorporou o preto dos góticos em suas ideias. "A ideia era dispersar qualquer tipo de enfeite (...), transformando-as em objetos de desejo, após um período tão gritante como foram as décadas anteriores." (MIGUEL, 2014).

Conclui-se que o minimalismo é um estilo que só tem achado cada vez mais espaço no design, buscando um aperfeiçoamento de formas e cores, utilizando-se de materiais e técnicas diferenciadas. Influencia não somente nos produto como também no modo de consumo, uma vez que prioriza a qualidade e o necessário, o que reflete no contexto do movimento slow life.

\section{Slow fashion}

Em 2002, uma cidade no Japão decidiu por abolir o máximo possível do uso de transportes, constrói casas de bambu e tenta negociar as horas de trabalho. Kakegawa foi, então, a primeira cidade a se denominar slow no mundo. Que isso tenha acontecido no país mais workaholic do mundo, foi surpreendente, mas mais do que isso, fez muitos ao redor do mundo questionarem sobre seu estilo de vida e o que deve-se priorizar no cotidiano (SARATE, 2011).

Vivemos em um período em que estar sempre ocupado é sinônimo de vida de sucesso, mesmo que não se sabe exatamente o porquê ou a finalidade de tudo isso. Bauman (2001) já apontou que é necessário que o ser humano descanse o corpo e a mente para poder desfrutar de suas tarefas, achar um ponto de equilíbrio entre o ócio e o trabalho, apreciando cada momento.

Vê-se, então, pessoas e grupos já em busca de novos caminhos para se obter uma vida mais equilibrada, perseguindo uma maior qualidade para sua vida e seu tempo. O slow life, tendo suas primeiras aparições nos anos 80 na Itália, ganha força no século XXI e é uma corrente que desafia o excesso em que vive-se na cultura contemporânea, tendo como acrônimo para "sustentável, local, orgânico e whole"(BUENO, 2016). Vem tendo grande força em áreas como moda, educação, alimentação, entre outros.

$\mathrm{Na}$ área da moda, denominando-se slow fashion, busca-se uma fortalecer a conexão entre o consumidor do produto e o designer criador, também procurando maneiras de redefinir os valores sociais em relação ao consumo de moda. Sendo assim, um movimento que prioriza o esmero, a qualidade e a produção pensada a longo prazo (JOHANSSON apud. SILVA et al., 2016).

O designer responsável busca pensar todo o processo de produção, desde de suas matérias primas até o descarte do produto, pesquisando opções que conscientize o cliente sobre o novo modelo de agir em relação ao consumo (SILVA et al., 2016). Foca-se em criar produtos com design 
atemporal, de qualidade e ressaltando o aspecto emocional, criando-se vínculo com o produto seja por meio do seu material, modelagem ou conforto (DELLA MEA, 2014).

Nota-se uma preocupação com o meio-ambiente e com a saúde mental do ser humano quando se trata do slow life, tendo o slow fashion como aplicação, pensando no conforto em que usufruir-se-á e em seu impacto ambiental, empenhando-se em criar um produto com material sustentável e durável.

\section{Design minimalista para slow fashion}

Minimalismo e slow life vem sendo amplamente discutidos na comunidade acadêmica por algumas décadas e, com o surgimento da geração $\mathrm{Y}$ e $\mathrm{Z}$, muito está sendo questionado sobre o estilo de vida que se tornou vigente no mundo inteiro. Mesmo que timidamente, mais de $1 / 4$ dos jovens entrevistados pelo website Nielsen desejam residir em bairros residenciais ao invés de espaços urbanos e menos de $10 \%$ ambicionam ter filhos (NIELSEN, 2016), detectado-se um desejo maior de se valorizar antes de qualquer cobrança social.

Com as mudanças sociais, o design se adapta, refletindo os desejos e necessidades da sociedade. Nota-se, então, uma preocupação no desenvolvimento de tecnologia limpa aplicada no cotidiano, juntamente com um design voltado para o conforto e o atemporal.

Na moda, vê-se documentários como "The True Cost" (MORGAN, 2015) que expõe a cadeia de moda do fast fashion e suas falhas, uma vez que esse sistema, que surgiu em 1890 e ainda é vigente, estimula o consumo além do necessário, buscando a autoafirmação e status no seu meio social (Box 1824, 2015).

Porém, na década de 90, surgiram uma nova onda de conscientização ambiental alertando o mundo sobre as consequências do consumo desenfreado e, mesmo com pouca atenção sendo dada por parte dos políticos e da mídia, foi o surgimento de um movimento que veio à ser denominado recentemente como Lowsumerism (Box 1824, 2015).

A ansiedade gerada pela compulsão por comprar, seguida por um aumento na taxa de suicídio em 10\% desde 2002 (BBC Brasil, 2017) e a constatação de que 1/3 dos recursos naturais da Terra foram consumidos (Box 1824, 2015), alerta a mídia de que algo precisa ser mudado, não só o consumo de produtos "verdes". Surge em 2010 o conceito de consumo compartilhado, com empresas como a Netflix, Uber e Spotify, reduzindo o consumo físico e priorizando o acesso acima da posse, porém não reduzindo o desejo de consumir.

\subsection{Análise de fatores}

Para a análise de fatores utilizar-se-á a ferramenta desenvolvida por Bruno-Faria e Alencar (1997), denominado Indicadores de Clima para a Criatividade (ICC), com o intuito de comprovar que ao adequar-se uma empresa ao minimalismo voltado para o slow fashion permite-se um estímulo à criatividade no ambiente de trabalho, sendo esta de suma importância para o crescimento empresarial atualmente, caracterizado por uma dinâmica acelerada e imprevisível que o mundo globalizado nos impõe (BRUNO-FARIA e ALENCAR, 1997).

Como fatores favoráveis, nota-se uma maior liberdade de ação, tratando-se aqui da análise da possibilidade de agir de diferentes formas dos profissionais em seu entorno, sendo este o pilar do slow fashion, clamando por uma maior liberdade tanto de criação quanto de produção e não valorizando cópia, o que muito acontece no sistema fast fashion.

O segundo fator é o "incentivo a ideias novas", tratando-se de uma sequência do primeiro item, focando-se nas ideias do criador sem levar em consideração as ações que o elvolve, onde denotase a procura por novas soluções constantemente pensando nos impactos socio-ambientais e a ampliação de materiais disponíveis, utilizando-se materiais como couro de abacaxi, tecido com PET, fibras naturais e orgânicas, entre outros (GUERRA, 2015).

Como conseguinte, o terceiro fator avalia a "disponibilidade de recursos materiais", aqui levando-se em consideração a facilidade de se obter o recursos para se fabricar o produto desejado e, como dito no parágrafo anterior, vê-se no slow fashion como pré-requisito o conhecimento de materiais alternativos, sua origem e qual seu futuro, buscando o balanceamento tão requerido dentro do movimento e a utilização daquilo que se tem acesso, sem solicitar por matéria prima que exija disperdícios de recursos. 
Os fatores desfavoráveis de acordo ainda com Bruno-Faria e Alencar (1997) iniciam-se com um fator imprescindível para o movimento slow: o tempo. Apontado por Guerra (2015) como algo positivo, o fator "excesso de serviço e escassez de tempo" não se dá ao slow fashion como negativo por se ter como objetivo o prolongamento da ação em cada tarefa para valorizar a qualidade e se emancipar desta aceleração do tempo que existe no modelo de produção atual.

Como confirmação deste caso, vê-se alguns casos de estilistas de maisons de alta costura abrir mão de seus empregos ou mudar radicalmente o sistema de produção por dizerem que o ritmo atual não permite inovação na área, sendo impossível trabalhar de tal modo, como o caso de Anna Bonnevier, que se demitiu para abrir sua empresa homônima e aderir o sow fashion em seu sistema de criação e produção (GUERRA, 2015).

Outro fator desfavorável apontado é o "bloqueio de novas ideias", onde tem-se mais relação com a hierarquia da empresa do que qualquer outro fator, podendo-se haver chefes priorizando suas ideias às de seus empregados, sendo passível de acontecimento em qualquer instituição, independente do sistema aplicado.

Como continuação do segundo item considerado desfavorável, há a "resistência de ideias novas", que é propagada pela cultura de acomodação profissional, dificultando a elaboração de novas ideias, podendo-se ter esse fator como favorável no movimento slow fashion se enxergá-lo como um incentivo à repensar o sistema de Moda, refletindo sobre como com a ideia de roupas e tendências para o fenômeno da Moda.

\subsection{Resultados}

Partindo da análise de um ambiente de trabalho criativo desenvolvida (Imagem 1), chegou-se ao seguinte quadro de resultados:

Quadro 1 - Resultados

\begin{tabular}{|c|c|}
\hline \multicolumn{2}{|l|}{ Fatores Favoráveis } \\
\hline I. Liberdade de ação & $\begin{array}{l}\text { Pilar do movimento slow, abraça qualquer } \\
\text { tentativa de criar um movimento de diversidade } \\
\text { na moda }\end{array}$ \\
\hline $\begin{array}{l}\text { II. Incentivo à ideias } \\
\text { novas }\end{array}$ & $\begin{array}{l}\text { Busca-se novas soluçōes constantemente para maior } \\
\text { durabilidade do produto e redução dos impactos } \\
\text { negativos nos fatores socio-ambientais }\end{array}$ \\
\hline $\begin{array}{l}\text { III. Disponibilidade de } \\
\text { recursos materiais }\end{array}$ & $\begin{array}{l}\text { Tem-se grande disponibilidade de mateirias, uma } \\
\text { vez que intende-se utilizar materiais diferenciados } \\
\text { e provenientes de uma matéria prima de fácil acesso }\end{array}$ \\
\hline \multicolumn{2}{|l|}{ Fatores Desfavoráveis } \\
\hline $\begin{array}{l}\text { 1. Excessos de serviços e } \\
\text { escassez de tempo }\end{array}$ & $\begin{array}{l}\text { Autonomia do calendário de produção e coleção } \\
\text { feitas para durarem à longo prazo }\end{array}$ \\
\hline $\begin{array}{l}\text { II. Bloqueio de novas } \\
\text { ideias }\end{array}$ & $\begin{array}{l}\text { Fator independente do sistema, podendo existir ou } \\
\text { não, relacionado ao sistema de gestâo de pessoas e } \\
\text { a relaçáo hierárquica presente, podendo ser ou não } \\
\text { abusiva e bloqueadora. }\end{array}$ \\
\hline $\begin{array}{l}\text { III. Resistência a ideias } \\
\text { novas }\end{array}$ & $\begin{array}{l}\text { Oportuniza a repensar o modelo de Moda vigente } \\
\text { abrindo caminho à novas possibilidades }\end{array}$ \\
\hline
\end{tabular}

Fonte: Os Autores (2017) 


\subsection{Da teoria à prática}

Vemos, assim, o sistema slow consumerism fazer as seguintes perguntas ao consumidor:

- Você realmente precisa disso?

- Você pode pagar por isso?

- Você não está apenas querendo se encaixar ou afirmar sua personalidade?

- Você sabe a origem deste produto e para onde ele vai depois?

- Você não está sendo iludido pela publicidade e branding?

- Você acha que essa compra irá prejudicar o planeta?

- Quantas dessas compras você acha que o planeta pode suportar?

Tais perguntas nos guiam à uma moda repensada do zero. Pode-se utilizar, portanto, do design de sistemas para sustentabilidade, como por exemplo o Life Cycle Design (VEZZOLI e MANZINI, 2010), que repensa todo o sistema de produção desde a pré produção até o descarte e reciclagem. Consegue-se ver também tal método no slow fashion, que tem tido mulheres influentes na mídia apoiando tal ideia como a atriz Emma Watson, que posta no seu perfil na rede social Instagram roupas que buscam se enquadrar no sistema slow e também com estilo minimalista moderno.

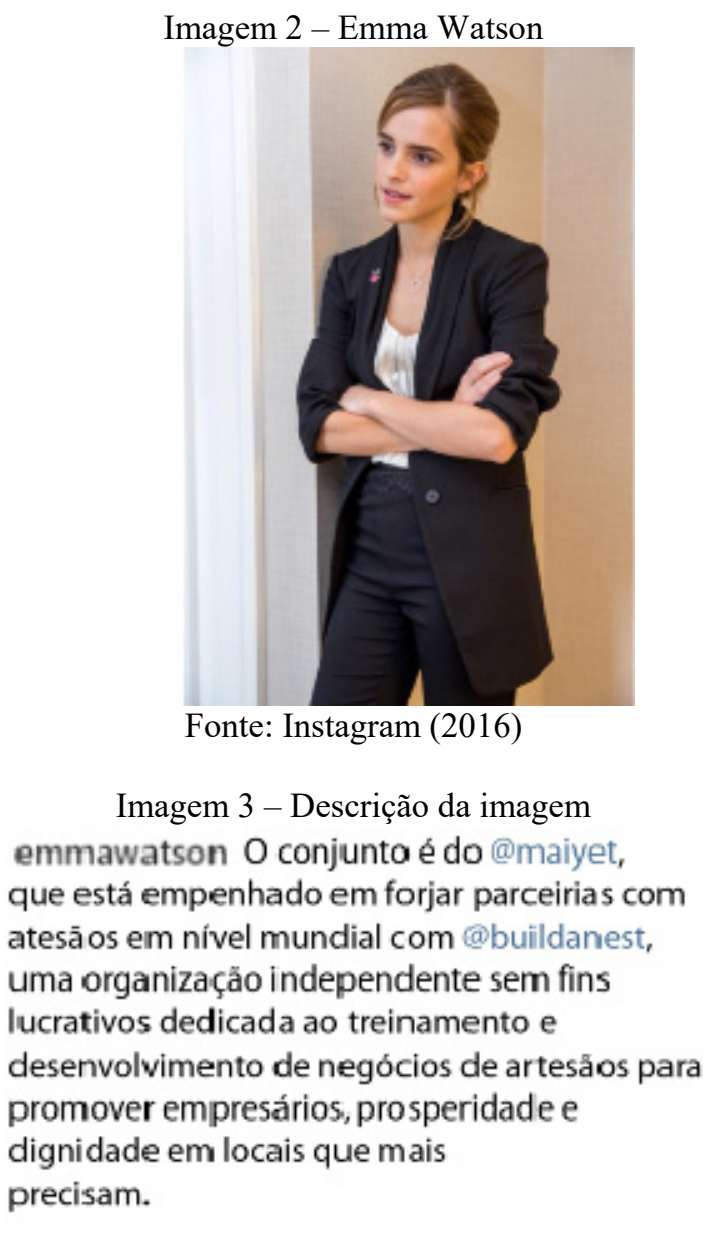

Fonte: Instagram (2016) tradição nossa (2017)

No Brasil, nota-se uma preocupação maior do movimento principalmente entre as mulheres, que virou aliado do movimento feminista brasileiro como meio de as mulheres se libertarem, especialmente por ser considerado o gênero que mais se atém ao consumo de modo desenfreado. Marcas vem aliando o minimalismo e o sistema slow para criar peças atemporais e duráveis, incentivando a compra pontual e de produtos de qualidade. Alguns exemplos são as marcas ADA, Brisa e Cantrelle Design, de roupas e acessórios, identificadas nas imagens 4 a 6 . 


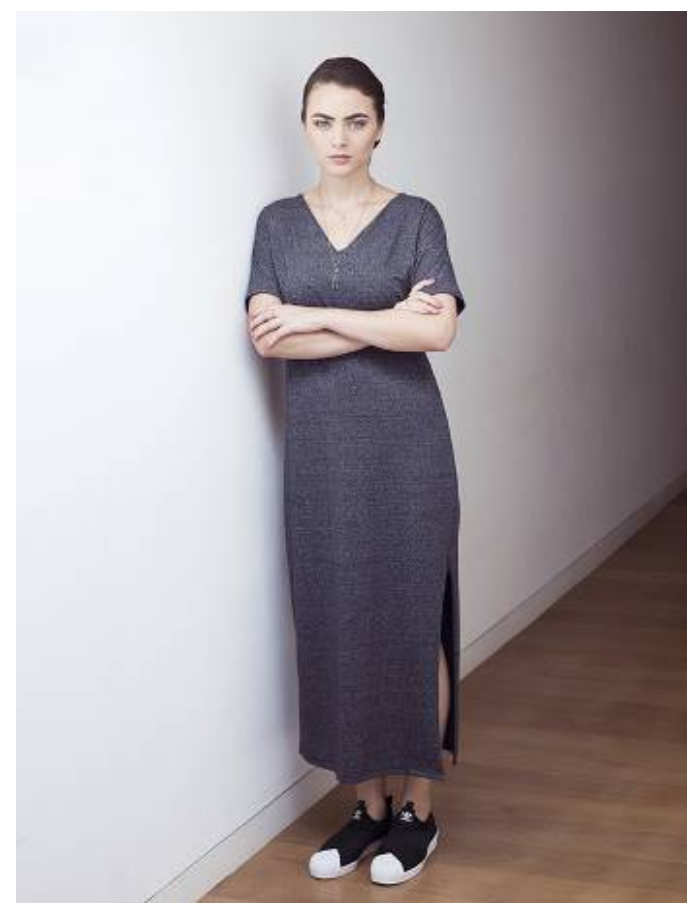

Fonte: Follow the Colors (2017)

A empresa ADA foi criada em 2016 e utiliza como matéria prima "fibras naturais feitas $100 \%$ no Brasil e que respeitam o direito dos animais" (Follow the Colors, 2017), também doando seus resíduos para um ONG que cuida de animais abandonados, que transforma tais resíduos em capas e camas para os cachorros e gatos que lá habitam. A empresa não segue tendências, produzindo suas peças manualmente e teve como inspiração para sua criação a freira Angelique Namaika, que lutou contra o feminicídio no Congo.

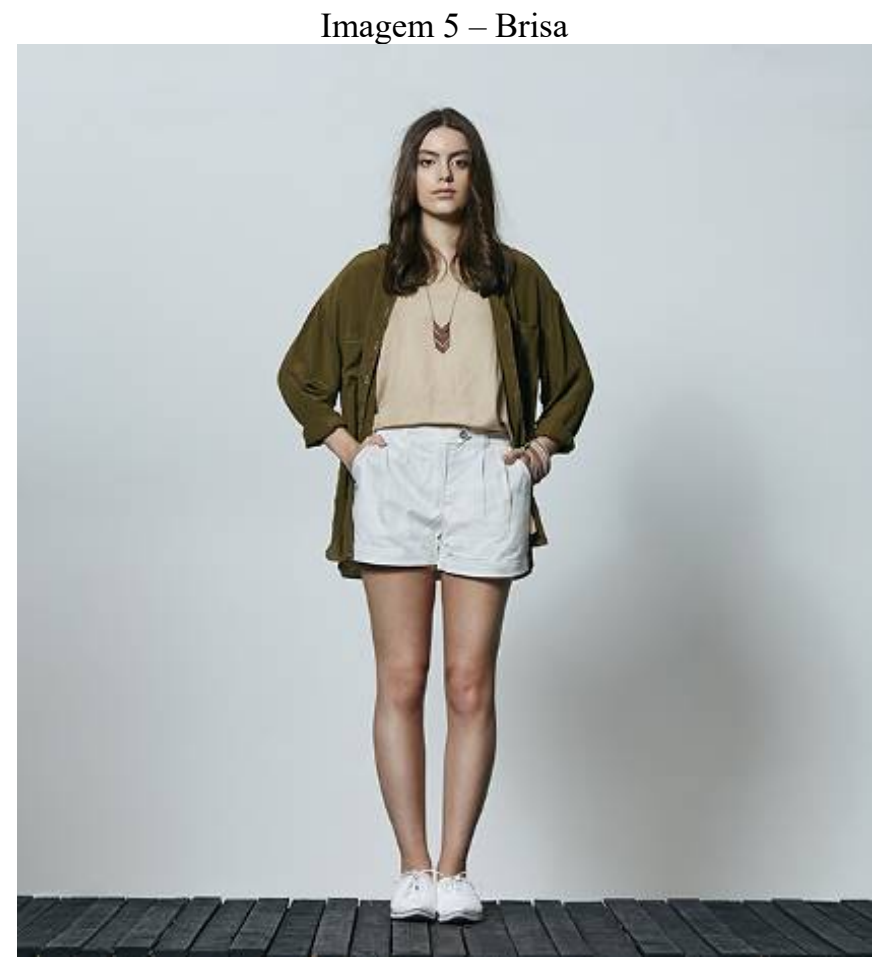

Fonte: Follow the Colors (2017) 
Anteriormente trabalhando como designer responsável para uma empresa de fast fashion, Tatiana sempre se considerou responponsável pelas suas criações e o impacto delas no meio socioambiental. Com sua demissão em 2015, ela teve um ano sabático em que trabalhou em uma fazenda de orgânicos em que ficou responsável pela composteira, descobrindo, no revirar dos restos de produtos, uma lã sintética que nunca se decompunha. Resolveu, a partir de tal descoberta, estudar o processo de produção do tecido e, assim, surgiu a criação da Brisa, com uma moda mais consciente e tecidos orgânicos ou reciclados, utilizando tingimento natural e confecção manual.

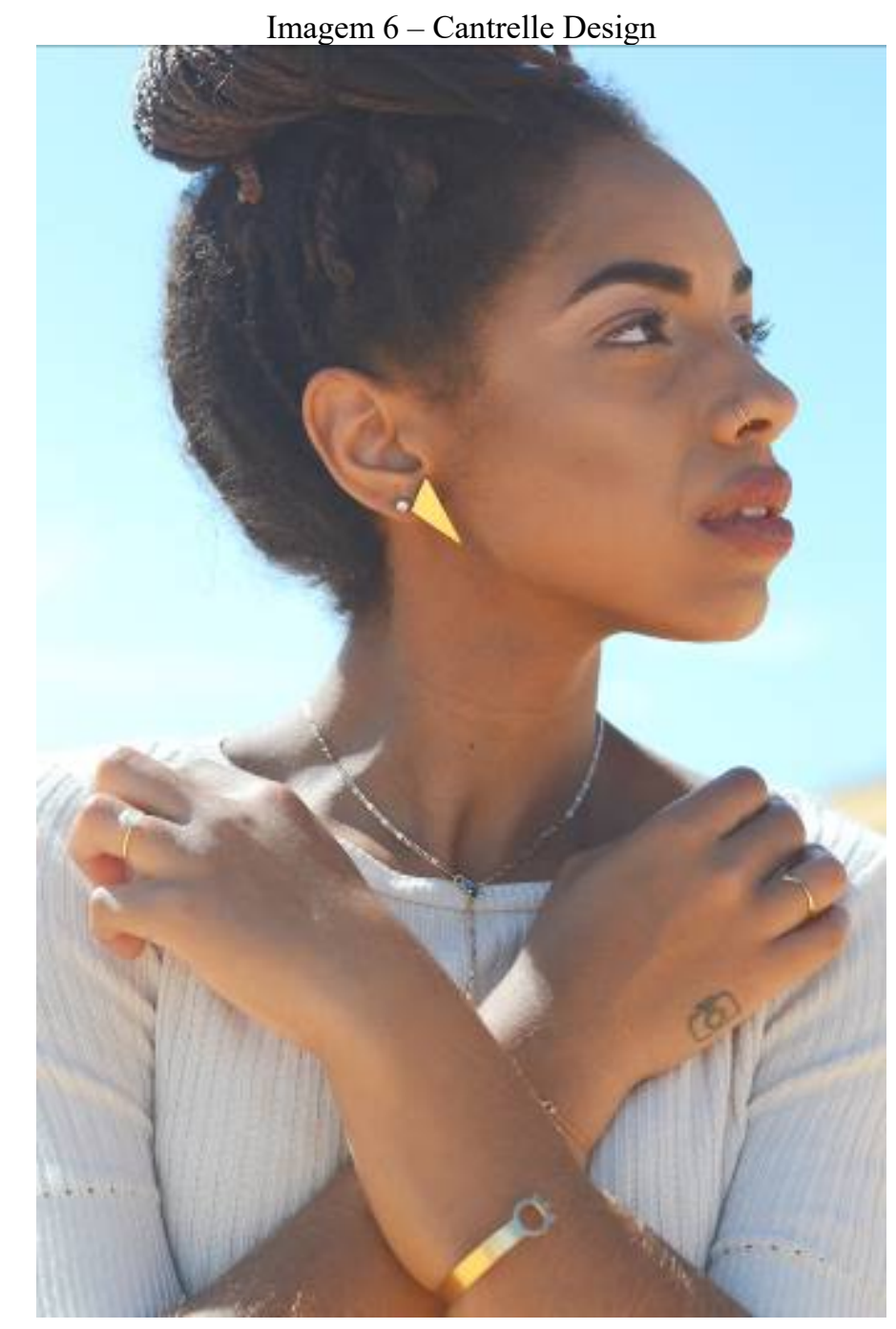

Fonte: A Autora (2017)

A empresa de semijoias Cantrelle Design foi fundada em 2015 para criar peças acessíveis e duráveis, unindo um design minimalista e moderno, utilizando como matéria prima o latão que, mesmo com seu impacto no meio ambiente, tem os seus efeitos minimizados por ser de alta durabilidade e porque a empresa recolhe as peças que não serão mais utilizadas para dar um novo fim.

\section{Conclusão}

Este trabalho foi desenvolvido com o objetivo de identificar os fatores favoráveis e desfavoráveis, utilizando-se o método de análise dos ICC, de se inserir o minimalismo para slow fashion em uma empresa de moda, enquanto também objetivava-se apresentar exemplos de estabelecimentos que já o fazem para comprovar a eficiência e positividade de tal tarefa.

A análise histórica e conceitual do design minimalista e do slow fashion expos a semelhança entre ambas práticas, demonstrando a importância de se pensar o sistema de produção de um produto 
em todas suas etapas de fabricação, desde a escolha da matéria prima até como este produto virá a ser descartado ou reutilizado, trabalhando com a qualidade, materiais diferenciados e em quantidades reduzidas, priorizando um design limpo e atemporal. $\mathrm{Na}$ análise de fatores, evidencia-se quão benéfico pode ser para a empresa aderir tais práticas à sua realidade, indicando somente uma situação desfavorável, sendo esta passível de ocorrer independente do sistema em que se trabalha, podendo-se concluir que tal aderência é positiva e eficiente, ainda mais ao considerar que o slow fashion defende uma personalização da moda para cada sujeito e o minimalismo prioriza a criação de um design significativo, o que cria uma relação emocional entre o indivíduo e o produto, levando aquele também a se relacionar com a marca.

Com a evidência de que o ritmo atual de produção não satisfaz mais os profissionais nele inseridos e muitos consumidores, cresce, inclusive no Brasil, o número de microempresas que levam em consideração os fatores socio-ambientais que a Moda vem impactando no último século. Tal mudança, mesmo que gradual, é de extrema importância, por levar a sociedade à repensar seu sistema de consumo e avaliar quem faz, como são feitos seus produtos e o impacto que estes causam no meioambiente. E isso é o que se tem visto ao retomar-se o slow fashion na cadeia criativa, a retomada de um pensamento crítico em relação a cada ação e a busca de uma conscientização geral a partir de um leitura de pensamento atual.

\section{Design with minimalism for slow fashion}

Abstract: The article aims to analyze the positive and negative factors of the application of a minimalist design focused on the slow fashion system in fashion companies, as well as the exposure of Brazilian companies that already do it in their work environment. In order to do so, it was used the tool developed by Bruno-Faria and Alencar (1997), called "Climate Indicators of Creativity" (CIC), which, through the analysis of a creative environment, seeks to evaluate the factors that influence expression of creative potential, both with individual employees and at the organizational level. In order to carry out such an investigation, an individual survey on minimalist design and slow fashion was carried out, analyzing its similarities and applications in the history of fashion design, and from this survey, to be able to apply the information in the CIC tool.

As a result, it was obtained a positive analysis of the work environment with the application of the minimalist design for slow fashion, observing a greater freedom of action, encouraging new ideas, availability of material resources, autonomy of the production schedule and the opportunity to rethinking the Fashion system, opening up new possibilities for creation and production. As the only ambiguous factor, one has the probability of blocking ideas through superiors, which may be positive or not.

As a conclusion, it is perceived that the practice of a minimalist design for a slow fashion system is positive and efficient, as well as creating an emotional link with the consumer through its products, also enabling society to rethink its mode of consumption, noting the resumption of a more critical thinking in each action, seeking a greater global awareness, given this through a reading of contemporary thinking.

Keywords: Minimalism; slow fashion; design; 


\section{Referências bibliográficas}

6 coisas que você deve saber sobre Flat Design. 2013. Disponível em <https://www.printi.com.br/blog/6-coisas-que-voce-deve-saber-sobre-flat-design>. Acesso em 05 de junho de 2017.

ADA: Marca brasileira traz peças minimalistas e veganas permitindo que as mulheres libertem-se das amarras da moda. 2017. Disponível em <http://followthecolours.com.br/style-freak/conheca-a-ada/>. Acesso em 06 de junho de 2017.

BAUMAN, Zygmunt. Journal of consumer culture. 2001. Disponível em <http://www.geocities.ws/visisto/Biblioteca/BAUMANN_Consuming_Life.pdf >. Acesso em 05 de junho de 2017.

BIZ, Eduardo. A desaceleração da fast fashion. 2013. Disponível em <https://medium.com/@box1824/a-desaceleracao-da-fast-fashion-ae721c80f4d2>. Acesso em 06 de junho de 2017.

BRUNO-FARIA, Maria; ALENCAR, Eunice. Indicadores de clima para a criatividade: um instrumento de medida da percepção de estímulos e barreiras à criatividade no ambiente de trabalho. Revista de Administração. São Paulo: v. 33, n.4, p. 86-91, outubro/dezembro 1998.

BUENO, Bárbara. Movimento slow life: desacelerando a vida. 2016. Disponível em $<$ https://pt.linkedin.com/pulse/movimento-slow-life-desacelerando-vida-b\%C3\%A1rbara-mantovanibueno>. Acesso em: 24 de maio de 2017.

Cantrelle Design: sobre nós. Sem ano. Disponível em <http://www.cantrelledesign.com.br/sobrenos-pg-59730>. Acesso em 06 de junho de 2017.

COFFANI, Ana Laura. 0 que é design minimalista? 2015. Disponível em:

<http://ideatore.com.br/?/post/119/o-que-e-design-minimalista/>. Acesso em 05 de maio de 2017.

DELLA MEA, Luciana. A moda em [re] evolução: slow fashion. 2014. Disponível em:

<http://www.autossustentavel.com/2014/05/a-moda-em-revolucao-slow-fashion.html>. Acesso em 05 de maio de 2017.

DENIS, Rafael. Uma introdução a história do design. 1999. São Paulo: Edgar Blüncher, 2000. 240 p.

Design minimalista: sua história e dicas práticas. 2013. Disponível em: <http://www.printi.com.br/blog/design-minimalista-sua-historia-e-dicas-praticas>. Acesso em 05 de junho de 2017.

ESCÓSSIA, Fernanda da. Crescimento constante: taxa de suicídio entre jovens sobe $\mathbf{1 0 \%}$ desde 2002. 2017. Disponível em <http://www.bbc.com/portuguese/brasil-39672513>. Acesso em 06 de junho de 2017.

Escola de Bauhaus. 2015. Disponível em <https://www.todamateria.com.br/escola-de-bauhaus/>. Acesso em 05 de junho de 2017.

Estilo de vida das gerações globais: quanto a idade influencia nosso comportamento? 2016. Disponível em <http://www.nielsen.com/br/pt/insights/news/2016/Estilos-de-vida-dasgeracoes-globais-quanto-a-idade-influencia-nosso-comportamento.html>. Acesso em 06 de junho de 2017.

FERREIRA, Eduardo; BRAGA, Marcos. Minimalismo e design minimalista. Sem ano. Disponível em <http://www.designemartigos.com.br/minimalismo-e-design-minimalista/>. Acesso em 05 de junho de 2017.

FERREIRA, Eduardo. Minimalismo, design minimalista e suas influências. 2008. Disponível em <http://www.iar.unicamp.br/lab/luz/ld/Arquitetural/design\%20de\%20lumin\%E1rias/minimalismo_desi gn_minimalista_e_suas_influencias.pdf>. Acesso em 05 de junho de 2017.

MANZINI, EZio; VEZZOLI, Carlo. 0 desenvolvimento de produtos sustentáveis: os requisitos ambientais dos produtos industriais. São Paulo. Editora da Universidade de São Paulo, 2002. 
Marca brasileira, sustentável e justa! A Brisa só utiliza matérias-primas orgânicas, além de tingimentos naturais. 2017. Disponível em < http://followthecolours.com.br/style-freak/brisa-slowfashion/?utm_campaign $=$ coschedule\&utm_source $=$ facebook_page\&utm_medium $=$ Follow $\% 20$ The $\% 20$ Colours\&utm_content=Marca\%20brasileira\%20sustent\%C3\%A1vel\%20e \%20justa!\%20A\%20Brisa\%2 0s\%C3\%B3\%20utiliza\%20mat\%C3\%A9rias-

primas\%20org\%C3\%A2nicas,\%20al\%C3\%A9m\%20de\%20tingimentos\%20naturais >. Acesso em 06 de junho de 2017.

MARCONI, Marina; LAKATOS, Eva. Fundamentos de metodologia científica. 2003. $5^{a}$ edição. São Paulo: Atlas S.A. 311 p.

MIGUEL, Bruna. O que é "minimalismo" na moda. 2014. Disponível em

<https://mondomoda.com.br/2014/02/21/entenda-o-conceito-do-minimalismo-na-moda/>. Acesso em 05 de junho de 2017.

NEUTE, Fernanda. 0 que é minimalismo?. 2013. Disponível em

<http://www.felizcomavida.com/minimalismo>. Acesso em 05 de junho de 2017.

NICOLAU, Raquel. ZooM: Design, teoria e prática. 2013. Disponível em <http://www.insite.pro.br/elivre/zoomraquel.pdf>. Acesso em 08 de junho de 2017.

0 que é design? Sem ano. Disponível em < https://www.marketdesign.com.br/blog/o-que-edesign>. Acesso em 08 de junho de 2017.

0 que é design e o que ele pode fazer pela sua empresa. Sem ano. Disponível em <https://www.sebrae.com.br/sites/PortalSebrae/artigos/o-que-e-design-e-o-que-ele-pode-fazer-pelasua-empresa,c636797d9ed77410VgnVCM1000003b74010aRCRD>. Acesso em 08 de junho de 2017.

REFOSCO, Ereany; OENNING, Josiany; NEVES, Manuela. Da alta costura ao prêt-à-porter, de Fast fashion a Slow fashion: um grande desafio para a Moda. 2011. Disponível em <http://www.periodicos.udesc.br/index.php/modapalavra/article/view/7808/5376>. Acesso em 08 de junho de 2017.

REVIDE. O conceito de fast fashion. 2010. Disponível em

<https://www.revide.com.br/editorias/moda/o-conceito-de-fast-fashion/>. Acesso em 24 de maio de 2017.

SARATE, Fernanda. O movimento slow life e a desaceleração da sociedade de consumo contemporânea. 2009. Disponível em < http://www.comunicacaoetendencias.com.br/wpcontent/uploads/2011/04/TCC-Fernanda-Sarate.pdf>. Acesso em: 24 de maio de 2017.

SILVA, Samantha; BUSARELLO, Raul. Fast fashion e slow fashion: o processo criativo na contemporaneidade. 2016. Disponível em

<http://www.usp.br/estetica/index.php/estetica/article/view/48/38>. Acesso em 05 de junho de 2017.

The rise of Lowsumerism. 2015. Disponível em:

<https://www.youtube.com/watch?v=jk5gLBIhJtA>. Acesso em 06 de junho de 2017.

TORRES, Marcos. Vamos falar sobre minimalismo. 2016. Disponível em:

<http://designculture.com.br/vamos-falar-sobre-minimalismo/>. Acesso em 05 de maio de 2017.

ZYSKO, Jefferson. Design dos anos 80. 2012. Disponível em

<http://www.cafecomgalo.com.br/design-dos-anos-80/>. Acesso em 05 de maio de 2017. 